\title{
A viagem e a escrita: trânsito entre gêneros e territórios em Martín Caparrós e Andrés Neuman
}

Renata Magdaleno

UERJ

\section{Resumo}

Através da análise de Una Luna, de Martín Caparrós, e Cómo viajar sin ver, de Andrés Neuman, este artigo reflete sobre os textos híbridos na literatura contemporânea da América Latina, uma mescla entre ficção, crítica e ensaio.

Palavras-chave: deslocamento; ensaio e ficção; escritor latino-americano.

\section{Abstract}

Through the analysis of Una Luna, a book from Martín Caparrós, and Cómo viajar sin ver, from Andrés Neuman, this article will think about hybrid texts in contemporary Latin American literature, a mix between fiction, criticism and essay.

Keywords: displacement; essay and fiction; Latin American writer. 


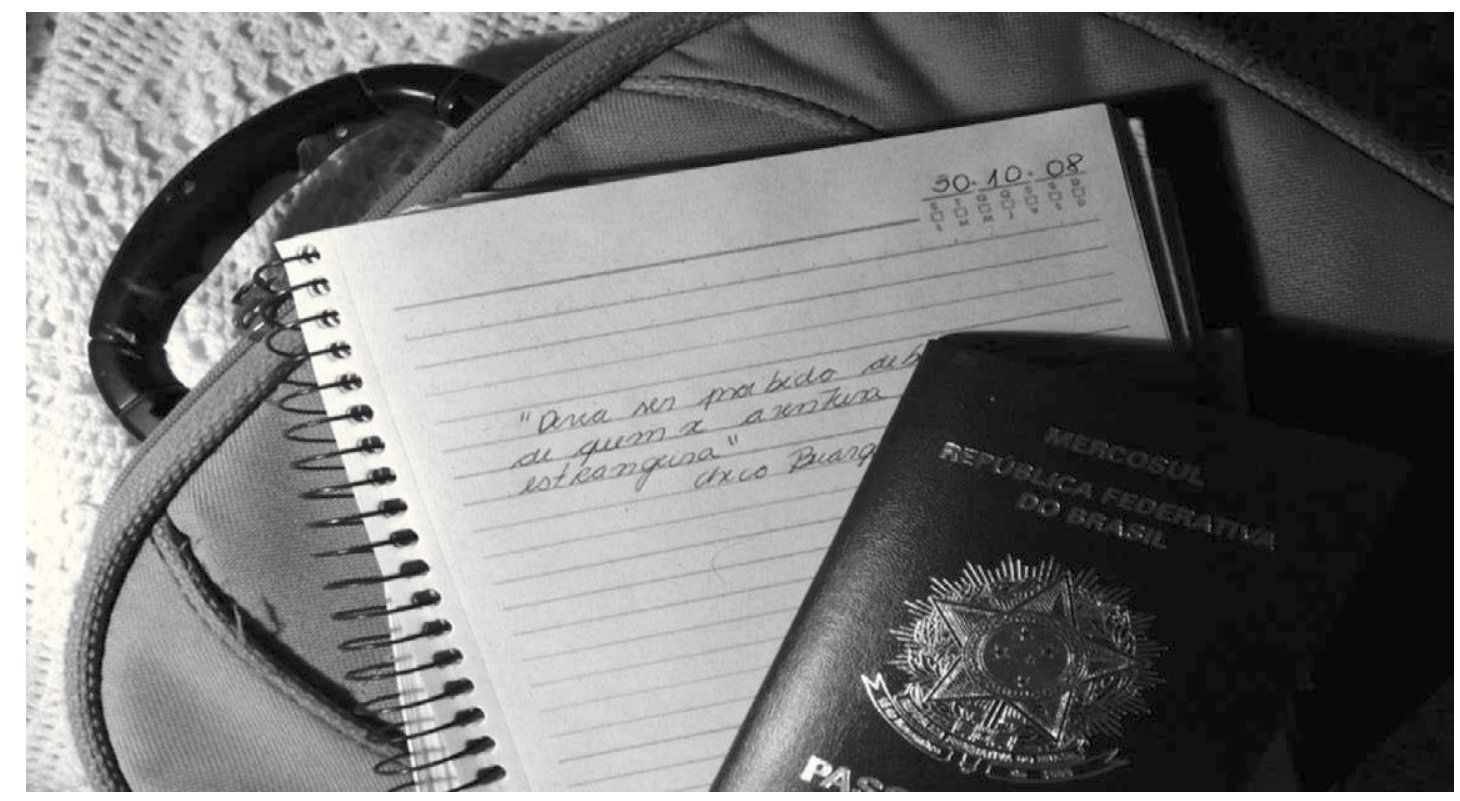

Chegada (fig.1)

"Devia ser proibido debochar de quem se aventura em língua estrangeira"

Chico Buarque

Comecei a refletir sobre a vida do escritor contemporâneo quando, pesquisando sobre a obra de Bernardo Carvalho, acompanhei os debates e entrevistas que ele fazia por conta do lançamento de O filho da mãe, em 2009. Sempre o mesmo discurso e uma rotina incessante que se repetia ao longo das cidades. $O$ que começou com uma ideia ganhou corpo anos depois, quando comecei a pesquisar sobre o assunto e resolvi fazer uma ponte entre o cenário das artes brasileiro e a literatura argentina.

Em uma livraria de Buenos Aires me deparei com um exemplar de Una luna, livro do escritor e jornalista argentino Martín Caparrós. Quanto mais avançava nas páginas, mais lembrava das muitas discussões de autores nacionais que tinha acompanhado naquele ano. Pensava em como, nos dias de hoje, um escritor precisa ceder às necessidades de um mundo globalizado, às tecnologias que nos permitem estar em pouco tempo em diferentes lugares, às leis de mercado que fazem os autores terem que sair de suas casas e conquistar leitores em conversas, palestras ou informais bate-papos. A literatura e seus muitos deslocamentos, as constantes idas e vindas dos autores contemporâneos. Caparrós conseguia, em seu livro, passar essa discussão para uma forma de escrita fragmentada, que acompanha e reflete essa rotina incessante. Numa mescla de ficção, ensaio e crítica. 
Tempos depois, em uma viagem a Rosário, na Argentina, encontrei Cómo viajar sin ver (2010), de Andrés Neuman, que trata de questão semelhante em um formato muito parecido ao de Caparrós. Neuman é ainda mais fragmentado. Os dois refletem sobre a viagem e a escrita e, nesse percurso, fazem pensar sobre a vida do autor contemporâneo e a posição de um escritor latino-americano no mundo globalizado.

"Aterrizo con parte de mí en otra parte". Cómo viajar sin ver, de Andrés Neuman, tem a rotina do escritor nos dias de hoje como pano de fundo. O livro foi escrito em quartos de hotel, aeroportos e em todos aqueles ambientes que Marc Augé classificou de não lugares, locais de passagem, característicos por exalarem uma não identidade. Quando o escritor se inteirou do percorrido que precisava cumprir por conta do Prêmio Alfaguarra, lamentou primeiramente não ter a possibilidade de conhecer mais detidamente os muitos destinos que precisava visitar. Depois, se entregou à oportunidade de ver diferentes paradas com o assombro do olhar da primeira vez. Seguiu o fluxo, até não ver mais nada, padronizar cada um dos lugares de passagem, ver todos quase que como um só. Os olhos, impossibilitados de enxergar algo em uma velocidade tão intensa, passaram a olhar para dentro.

Experiência semelhante desenvolve Martín Caparrós em Una luna (2009). A convite da Organização das Nações Unidas (ONU) ele viaja atrás das histórias dos imigrantes do mundo, que se deslocam, mudam de país em busca de melhores condições de vida, possuem histórias e vivem situações que pareceriam inimagináveis a qualquer pessoa com a vida assentada em um grande centro urbano. Em um único mês, ele precisa cumprir um percurso que inclui Kishinau e Monrovia, Amsterdam e Losaka, Pittsburgh e Paris, Madri, Barcelona, Joanesburgo. Tribos africanas arrasadas pela pobreza e cidades supermodernas.

Mas o ritmo é tão intenso que os relatos das pessoas que ele entrevista pelo caminho dão o tom da sensação que fica após cada encontro. São textos objetivos, sem emoção, impessoais, que apenas contam uma história, diferentes histórias, das mais tristes e trágicas às mais amenas, da mesma forma. $\mathrm{Na}$ velocidade da viagem, tudo adquire padronização, os relatos que ele escreve vão nessa mesma linha, e o leitor se depara com o diário de uma hiperviagem, como o próprio Caparrós denomina o seu "romance". Circulando entre aeroportos e quartos de hotel, com seus detalhes homogêneos, travesseiros sempre do mesmo tamanho, ambientes higienizados, o protagonista-escritor só pode aspirar recorrer a sua própria história e a suas lembranças.
1. NEUMAN, Andrés. Cómo viajar sin ver, 2010, p. 21. 
2. Existe uma diferença no contexto em que esses escritores produziram. Macedonio e Borges atuaram durante a época das vanguardas, movimento que marca a primeira metade do século XX na América hispânica. Enquanto no Brasil se vivia o modernismo, repensando o conceito e a produção da cultura nacional, os países da região estavam às voltas com as experimentações de novas formas e linguagens, inspirados nas vanguardas europeias. Já na década de 1990, há uma onda mundial de quebra de fronteiras dos gêneros literários, estimulada por uma série de fatores, como, por exemplo, a influência de novas tecnologias, dos meios de comunicação de massa e de um mercado cada vez mais acirrado. Em comum entre esses dois períodos, está essa tentativa de ir além de antigos padrões, de experimentar e transpor fronteiras entre gêneros. $\mathrm{Na}$ América Latina, a produção de autores como Borges e Macedonio ainda influenciou toda uma geração posterior de escritores, criando uma tradição na região de textos que mesclam ensaio e ficção.
Nos dois casos encontramos um texto que foge ao que comumente chamaríamos de romance, um diário de viagem que mescla ficção e memória e, aos pedaços, vai compondo a história de um percurso, fazendo pensar sobre uma série de temas e muito pouco sobre o que se avista pelo caminho. Estamos diante de uma mescla de memória, ensaio e ficção, com forte teor de crítica. Uma autoficção em que um autor-personagem reflete sobre a rotina dos escritores contemporâneos, pensa o lugar do autor latino-americano e, ao mesmo tempo, produz um texto que reflete exatamente o ritmo dessa vida acelerada dos dias de hoje, sem tempo a ser perdido e onde o mercado comanda e controla cada percurso, fragmentado, com ideias que não se conectam facilmente.

Flora Süssekind, em Papéis colados, detecta que a mescla de ficção e ensaio e/ou crítica e ensaio é uma marca da literatura latino-americana. No Brasil, a hibridez entre crítica e ensaio se firma a partir da década de 1980 . O crescimento editorial estimula, ao longo dessa década, o surgimento de uma crítica mais atenta, que pensa sua própria atuação e que busca uma melhor forma de inserção e de aceitação do leitor, depois de anos de uma linguagem hermética, inspirada nas teorias imanentistas europeias e inacessível ao público leigo.

No período, há ainda a dificuldade de se conseguir espaço nos jornais para a publicação de textos, já que o reduzido local destinado à literatura passa a ser reservado mais para resenhas e notícias dos lançamentos do mercado editorial. Um cenário que forçou uma adaptação por parte desse crítico, que atinge um meio-termo entre o crítico impressionista, característico do início do século, com um texto que se aproxima à crônica, e o teórico de formação acadêmica, que toma conta do cenário na metade do período. A década foi marcada por uma indústria cultural competitiva (o que só se intensifica ao longo dos anos), que defende o texto objetivo e vendável e vai contra qualquer texto argumentativo. $\mathrm{O}$ resultado foi uma crítica que se mescla ao ensaio e ganha ares mais acessíveis.

A ficção também ganha tintas de ensaio por influência de uma série de autores que marcaram a literatura da região. $\mathrm{Na}$ América Latina, escritores como Macedonio Fernández e Jorge Luis Borges produziram obras que, a todo momento, refletem sobre o próprio ato da escrita. Textos híbridos que mesclam a ficção, o ensaio e a crítica. Essa tendência também é acirrada a partir dos anos 1990, por uma onda mundial de hibridização do texto literário, por uma tentativa de testar e transpor os limites que costumavam definir os diferentes gêneros ${ }^{2}$.

Os textos de Caparrós e Neuman estão marcados por essa tradição, mas não apenas isso. Eles fazem questão de fincar sua escrita em um determinado período de tempo, produtos de 
um mundo globalizado, de um mercado competitivo, de uma rapidez que não deixa tempo para olhar o outro, de um encurtamento de distâncias que aproxima diferentes localidades e culturas, tornando suas paisagens homogêneas, marcadas pela impessoalidade e pelos padrões internacionais de aeroportos e hotéis. São textos que refletem em sua estrutura todo esse panorama de novas tecnologias.

Para Caparrós, por exemplo, o mundo contemporâneo mudaria não apenas o produto final, a escrita, mas também a forma de conduta de escritores e artistas de uma forma geral, aqueles que normalmente estariam movidos a buscar inovações.

Las tecnologías cambiaron tanto en los veinte últimos años que produjeron un mundo distinto, hipercomunicado, espectador, plagado de lo mismo. Si hay modelos que copiar es porque alguien inventó modelos. Y durante todo el siglo veinte por lo menos, los arquitectos - y los escritores y los pintores y los cineastas y los diseñadores y los músicos - supusieron que tenían que buscar lo nuevo, lo distinto. Ahora todo consiste en ver qué resucitan. Igual que las novelas. Me sabe un poco triste. ${ }^{3}$

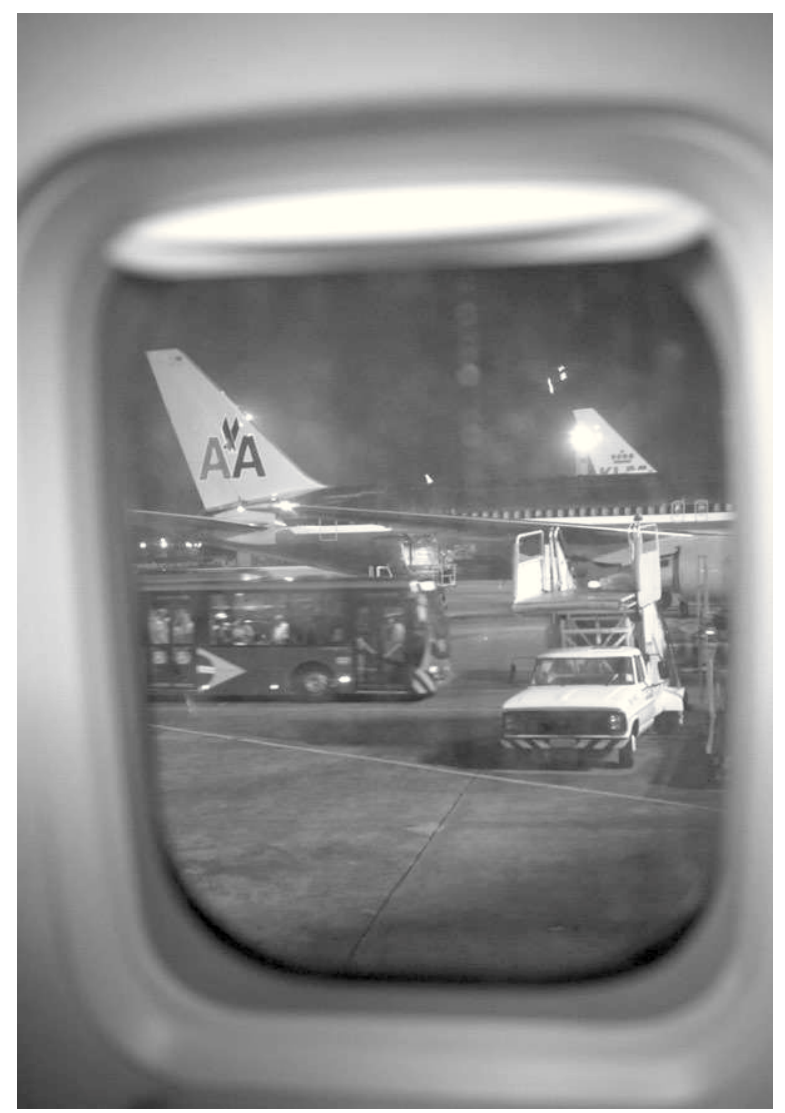

Viagens e diários (fig.2)

Aos escrever sobre estes dois autores, estou também comentando minha própria viagem. Viagem no sentido metafórico, pesquisa, tatear sobre interpretações e reflexões, mas também
3. CAPARRÓS, Martín. Una

luna, 2009, p. 178. 
deslocamento físico. Também li as duas histórias em trânsito e fui anotando aos pedaços as ideias que foram surgindo. A diferença é que não resisti. Em vez de produzir também um artigo aos pedaços, uma crítica feita de microensaios, trouxe o texto para casa e fui costurando, com linhas do passado e do futuro, e produzindo um formato que fica pelo meio do caminho.

Nascido em 1957, em Buenos Aires, Caparrós tem um perfil viajante. Já viveu em Madri e Nova York, viajou a trabalho por diversos países e publicou cerca de vinte livros entre romances, crônicas, relatos de viagem, ensaios e narrativas de jornalismo literário. Foi editor de revistas e jornais argentinos importantes, e encontramos sua fala em diversos meios de comunicação, opinando em entrevistas sobre os mais diferentes assuntos, sobre o jornalismo, sobre a condição do mundo e acerca dos problemas climáticos. É presença comum em feiras e eventos literários. No caso de Una luna, viaja contratado pela ONU com o objetivo de entrevistar os mais diferentes tipos de imigrantes, aqueles que se deslocam com o intuito de buscar melhores condições de vida. Caparrós funciona como um colecionar de histórias de vida relacionadas ao deslocamento.

Ele faz o percurso do explorador às avessas. Se a América Latina foi marcada por relatos de viajantes, pelo olhar de um outro europeu que julga e descreve conforme avista as diferenças, o autor tem uma função similar. Mas seus relatos são produzidos em outro tempo. É como se, para atingir a diferença, ele precisasse visitar as tribos mais recônditas. Mesmo assim, seus relatos são padronizados, diminuindo a distância, como se fossem produto de um olhar cansado, que não consegue mais avistar o novo. E ele conclui que, por mais distintas que sejam as trajetórias de vida, todos querem o mesmo: conseguir estabilidade e melhores condições.

Ainda sentado no avião, se dirigindo para o seu primeiro destino, o personagem-autor olha para o céu e percebe que a lua está cheia. Será assim ao longo de todas as 181 páginas de Una luna, enquanto percorre a França, a ex-União Soviética, países da África, Amsterdam, El Salvador... Os destinos são os mais variados, e as histórias que encontra pelo caminho, tristes ao extremo: como a de Natalia, uma jovem vendida pelo seu marido a uma rede de prostituição; a de Richard, exilado por conta das guerras civis na Libéria, que presenciou a avó sendo devorada por guerrilheiros; a de uma mulher estuprada; a de um menino soldado... O que separa uma história de outra, no livro, é o estilo do escritor, que pula das reflexões existenciais para o tom frio e superficial das entrevistas. O que separa um caso de outro dentro do trajeto percorrido pelo narrador são apenas algumas horas de voo, o cheiro das salas de espera vips 
dos aeroportos, sempre o mesmo, onde quer que esteja. Apesar dos muitos encontros, são histórias que parecem tocar o autor-viajante apenas na superfície e, quanto mais ele se desloca, mais parece imerso em suas próprias reflexões. "Paso. Por los lugares paso: en este viaje los cruzo, nos rozamos."

No pular desenfreado entre os países, ocorrem mudanças tão drásticas, acontecidas em espaços de tempo tão curtos, que fazem o autor denominar seu deslocamento de hiperviagem. Ele compara a velocidade com o navegar pela internet, o abrir e fechar dos links clicados na rede. A cada uma dessas investidas, entramos em um novo mundo, temos acesso a uma outra possibilidade de vida. Mas a velocidade é tão grande que não é possível se aprofundar em nenhuma delas. Uma nova história, assim como se fosse o clicar em um link, o espera, fazendo com que deixe tudo o que viu rapidamente para trás. É preciso se deslocar novamente e tudo o que presenciou ganha a aparência de um filme, assistido e já esquecido.

O pano de fundo da história, esse tempo acelerado, nos leva a pensar nas teorias desenvolvidas pelo sociólogo polonês Zygmunt Bauman para descrever a vida contemporânea, um tempo que ele classifica com a expressão "modernidade líquida”. O termo caracterizaria uma sociedade que seguiria, em todos os seus setores, as leis do consumo: rapidez; disponibilidade; envolvimentos superficiais que possibilitem dissociações rápidas assim que novas e aparentemente melhores oportunidades apareçam pelo caminho... Como se tivéssemos nos acostumado a viver adotando as leis de consumo em nossas próprias relações pessoais.

Em Identidade (2004), livro composto por uma longa entrevista, em que Bauman conversa com o jornalista Benedetto Vecchi, o sociólogo reflete sobre esse movimento contemporâneo usando sua própria vida como exemplo. Ele, que deixou a Polônia na década de 1960, proibido de lecionar em sua terra natal, para ser acolhido por uma universidade inglesa. "Depois disso, naturalizei-me britânico, mas, uma vez recém-chegado, será possível abandonar essa condição algum dia?"5, se pergunta o autor, refletindo sobre a condição de estrangeiro, daquele que, por mais que esteja naturalizado e adaptado ao país que escolheu como moradia, se sente sempre "entre", em um lugar do meio.

Andrés Neuman também ressalta um panorama de identidades híbridas em seu romance, um sem fronteiras que se estende para a forma de escrita que elegeu. Logo nas primeiras páginas, ele lembra do encontro com argentinos na Feira do Livro de Madri. Sete jovens com um sotaque estranho e uma fala mista chamam a sua atenção. São filhos, netos e bisnetos de argentinos que, como ele, deixaram sua pátria ainda na in-
4. Ibidem, 2009, p. 59 .

5. BAUMAN, Zygmunt. Identidade, 2004, p. 15. 
fância e foram viver com suas famílias na Europa. Enquanto Caparrós mescla as reflexões sobre a rotina contemporânea, sua própria escrita e existência, em uma espécie de balanço de vida, realizado às vésperas de o autor completar 50 anos, Neuman faz um balanço da literatura que encontra pelo caminho, recorre a leituras do passado, de escritores clássicos, e compara com o cenário atual, os contos dos jovens autores de cada região.

Sua viagem é pela América Latina. Caparrós lembra da juventude na Europa, olha com nostalgia as mudanças no mundo e o reflexo destas em sua própria escrita e na produção dos artistas contemporâneos. Neuman, de 37 anos, faz uma espécie de percurso de volta para casa. Nascido na Argentina, mas vivendo na Espanha desde a adolescência, o autor lembra de onde vivia, dos locais que frequentava e das andanças que fez na região enquanto era criança, do cenário político e literário que encontra, e investiga a literatura de onde passa. $\mathrm{Na}$ Argentina, por exemplo, ele discute contos de autores como Washington Cucurto, Mariana Enriquez, Gonzalo Garcés. E lembra (comparando e analisando seus vestígios na produção atual) as leituras que marcaram a região, como Jorge Luis Borges e Silvina Ocampo. No Ururguai, fala de clássicos como Juan Carlos Onetti e Eduardo Galeano, mas também cita crônicas e artigos de Gustavo Escanlar, falecido em 2010, aos 48 anos. No Chile, se sente perseguido pela marca de Bolaño.

Ao adotar um formato fragmentado ao extremo, que lembra pequenas anotações feitas em um caderno durante uma viagem, o autor discute os reflexos de uma rotina competitiva e globalizada e de novas tecnologias na produção dos autores de hoje. Ele mesmo explica, nas primeiras páginas de seu diário, que não quer fazer anotações para depois, em casa, escrever um livro em cima das ideias que surgiram. Mas fazer das próprias anotações um livro. Se não é mais possível o tempo do "ócio" criativo, se o mercado atual impõe a presença do autor em diferentes eventos e países, então, é preciso escrever nessas brechas, aproveitar ao máximo o que o novo panorama impõe. Um programa que afeta, ele também, a arte produzida. Ángel Rama defendeu que a literatura produzida na América Latina sempre veio marcada por uma escrita corrida, desenvolvida nas horas vagas, dividida entre empregos fixos que os autores precisavam adotar para se sustentar. Característica de países onde nunca foi possível (com raras exceções) viver exclusivamente da literatura. No momento atual, cada vez mais escritores conseguem se dedicar ao ofício, mas precisam se submeter ao ritmo intenso de um mercado competitivo e que exige sua presença. Essa rotina também estaria marcando as produções artísticas?

O narrador-autor de Cómo viajar sin ver avisa: "No quería por nada en el mundo que este diario derivase en una crónica 
social del gremio literario, para mi uno de los géneros más autocontemplativos y aburridos que existen". Mas suas notas em trânsito levam sim a pensar em como a escrita literária se comporta neste novo panorama, em como os gêneros perdem suas características em uma mescla e em perda de fronteiras cada vez maiores. Como classificar Cómo viajar sin ver e Una luna? Microensaios, diários de viagem, romances, autoficções...?
6. NEUMAN, Andrés. Cómo viajar sin ver, 2010, p. 15

7. Ibidem, p. 41.

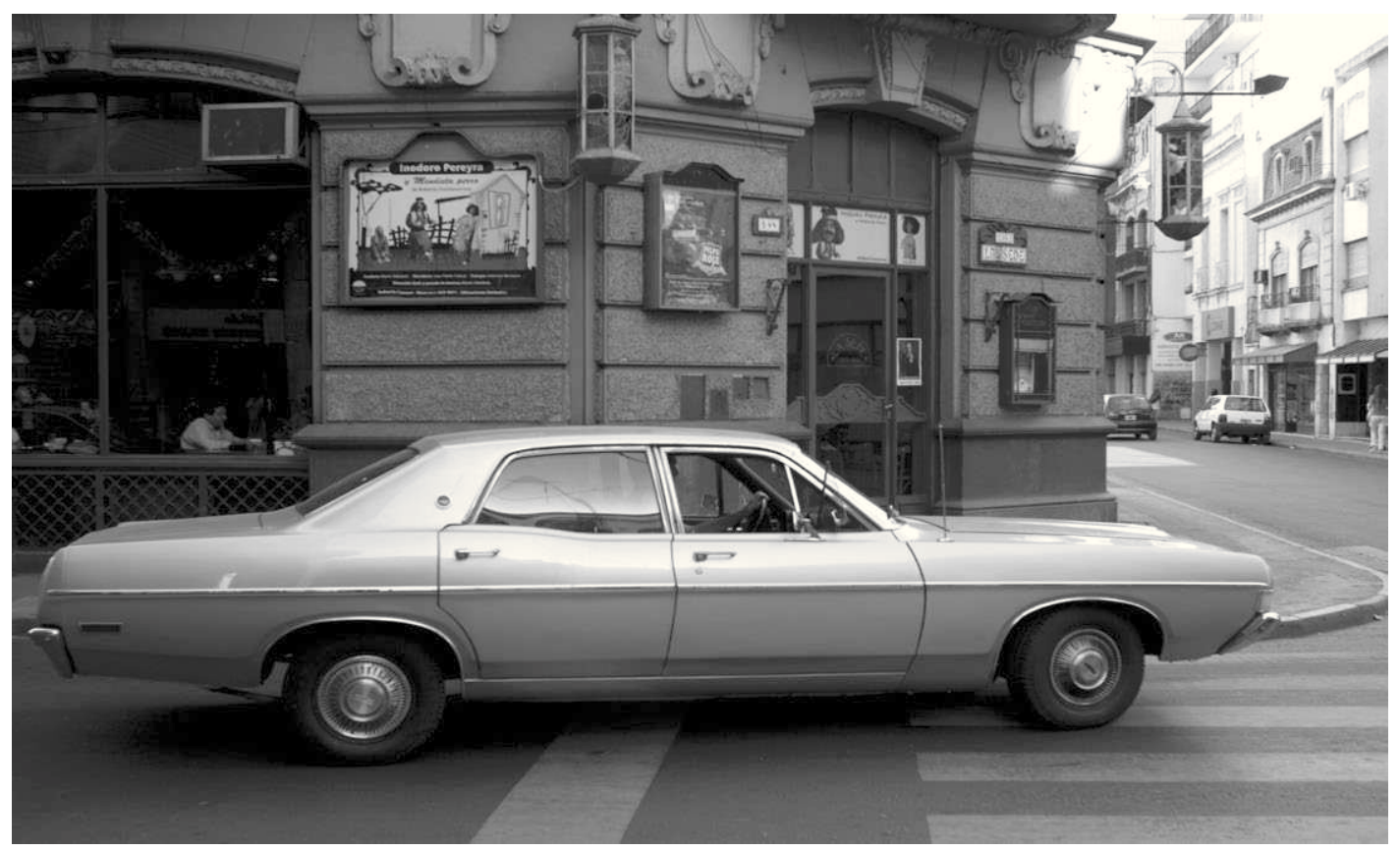

Porque a vida é feita de encontros (fig.3)

Começo a mesclar teorias. Lembro do polêmico texto de Josefina Ludmer sobre a literatura argentina produzida depois do ano 2000 ("Literaturas posautonómas", 2006), de livros de Florencia Garramuño como A experiência opaca (2013) e Frutos estranhos (2014). No meio das reflexões, me deparo com o seguinte trecho:

Al bajar del avión me cruzo con la profesora y crítica Josefina Ludmer, con quien he viajado sin saberlo. Nos saludamos. Le pregunto por una antigua alumna suya que conocí hace años. Su caso era curioso. Sin duda brillante y perfectamente bilingüe por razones familiares, no sabía si escribir su primera novela en inglés o en español. Me intereso por ella y su novela fantasma. Ludmer me contesta que la empezó en español y la terminó en inglés. That's fair, no?

O encontro com Ludmer, a mescla de idiomas, levam a pensar sobre uma perda de fronteiras que aparece refletida no mesmo texto que discute o assunto, como um reflexo do conteúdo na forma. Como Ludmer faz nas discussões que desenvolveu no texto "Literaturas posautónomas" e em suas derivações. 
8. CONTRERAS, Sandra.

"Cuestiones de valor, énfasis del debate”. Boletín, 2010.
Ela detecta a perda extrema de fronteiras nas publicações a partir do novo milênio, até o ponto de ficarmos na dúvida se estamos diante de um texto que pode ser classificado como literatura ou não. As críticas que recebeu foram muitas. Suas observações motivaram a produção de uma série de artigos e ensaios que apontavam, por exemplo, uma longa trajetória para a discussão sobre o fim da literatura ${ }^{8}$, o que faria com que a teórica apertasse uma tecla já há muito trabalhada. As próprias vanguardas já haviam despertado, no início e no meio do século XX, espanto nos críticos do período e reflexões sobre como pensar e analisar novos e revolucionários formatos. Ludmer também faz um link entre as mudanças no formato da ficção e as pressões do mercado, o que também já foi discutido por outros teóricos ao longo do século passado, como, por exemplo, Hal Foster.

Mas, apesar de toda a discussão que proporcionou, me parece muito significativa a forma como a pesquisadora produz um texto crítico que reflete na forma o seu conteúdo. Ao detectar esta "nova" literatura e ao pensar sobre como lê-la, ela estende a discussão até a crítica, produzindo um texto que, também ele, perde os formatos tradicionais de como uma crítica literária era caracterizada ou vista. Seus artigos são publicados em seu blog pessoal, sem bibliografia em anexo, com uma linguagem fragmentada que vai além da simples mescla com o ensaio e que se identifica também com um panorama de novas tecnologias, que afetariam as formas de escrita e de leitura.

Florencia Garramuño também explora os limites e as características do que poderia ser considerado arte e literatura nos dias de hoje em Fruto estranho (2014). O que definiria a produção contemporânea seria justamente essa mistura inusitada? Ela se detém em obras nas quais se entrecruzam música, cinema, literatura, fotografia, fragmentos de e-mail, discursos antropológicos, uma forma de escrita fragmentada característica de mídias sociais. Entre os livros que analisa estão romances de autores como Luiz Ruffato e Bernardo Carvalho. A literatura dialoga com outras artes, fazendo o leitor pensar sobre os limites que definiriam o que caracterizamos, por exemplo, como romance. Com foco na produção de Brasil e Argentina, o percurso de inovações e experimentações que analisa se inicia nos anos 1960 e se intensifica e se radicaliza nos dias de hoje.

Os livros de Caparrós e de Neuman desenvolvem na literatura aquilo de Ludmer e Garramuño trabalham na teoria. E não são apenas exemplos de publicações que estendem limites, experimentam formatos e, por esse motivo, exemplificam o que as duas detectam. Mas, por possuírem um forte teor crítico, contribuem e fazem parte desse debate.

Tenho o impulso de usar os dois livros como aparato teó- 
rico em um próximo artigo. O que diferenciaria os textos críticos dos ficcionais, quando trabalhados dentro desse contexto? A biografia de seu autor? Neuman é um escritor jovem, mas já reconhecido, e com um cargo como professor de literatura na Universidade de Granada no currículo. Seria o suficiente? As experimentações formais, a expansão das fronteiras, tornam a diferenciação cada vez mais difícil, até o ponto em que parece não fazer mais sentido pensar na necessidade de diferenciação. 


\section{Referências}

AUGÉ, Marc. Não-lugares: Introdução a uma antropologia da supermodernidade. Campinas: Papirus, 2004.

BAUMAN, Zygmunt. Identidade. Rio de Janeiro: Zahar, 2004.

CANCLINI, Nestor García. Latino-americanos à procura de um lugar neste século. São Paulo: Iluminuras, 2008.

CAPARRÓS, Martín. Una luna. Barcelona: Anagrama, 2009.

CONTRERAS, Sandra. "Cuestiones de valor, énfasis del debate”. Boletín. n. 15, out. 2010. Disponível em: http:// www.celarg.org/int/arch_publi/contreras.pdf. Acesso em: 26 de agosto de 2014.

LUDMER, Josefina. "Literaturas posautónomas”. Disponível em: <http://www.lehman.cuny.edu/ciberletras/v17/ludmer. htm>. Acesso em: 29 de maio de 2014.

. Aqui América Latina: Uma especulação. Belo Horizonte: Editora UFMG, 2013.

GARRAMUÑO, Florencia. Experiência opaca. Rio de Janeiro: Editora UERJ 2013.

. Frutos estranhos. Rio de Janeiro: Rocco, 2014.

NEUMAN, Andrés. Cómo viajar sin ver. Buenos Aires:

Alfaguara, 2010.

RAMA, Ángel. Literatura, cultura e sociedade na América Latina. Belo Horizonte: Editora UFMG, 2008.

SÜSSEKIND, Flora. Papéis colados. Rio de Janeiro: Editora UFRJ, 1993. 